\title{
Magnitude and associated factors of health professionals' attrition from public health sectors in Bahir Dar City, Ethiopia*
}

\author{
Kiros Atnafu, Gebeyaw Tiruneh, Tadese Ejigu \\ Intra Health International, Bahir Dar City, Ethiopia; ${ }^{\#}$ Corresponding Author: tade_et@yahoo.com, katnafu@gmail.com
}

Received 21 August 2013; revised 28 September 2013; accepted 9 October 2013

Copyright (C) 2013 Kiros Atnafu et al. This is an open access article distributed under the Creative Commons Attribution License, which permits unrestricted use, distribution, and reproduction in any medium, provided the original work is properly cited.

\begin{abstract}
Background: Attrition of health professionals from public health sectors is found to be a barrier to effectiveness of health systems and to provide essential health service to population. In Ethiopia, the public health system is the major provider of health care service to the people. In particular, the poor segment of community uses public hospital, health centers and clinic, since the private health facilities are inaccessible and unaffordable to them. The aim of this study was to determine the magnitude and factors associated with health professionals' attrition from public health sectors in Bahir Dar city. Methods: A Facility based cross-sectional study was conducted in September-October 2012. All inclusive sampling techniques of five years document reviews were used to select 727 health professional documents. Quantitative and qualitative data were collected using structured questionnaires and indepth-interview guides respectively, by trained data collectors. Descriptive statistics (frequencies, proportion and chi square test) were used to describe the study population in relation to relevant variables. To identify independent predictors of attrition, only variables that were statistically significant during bivariate analysis were entered into multiple logistic regression models to control the effects of confounders. Pvalues $<0.05$ were considered as statically significant. Result: The attrition rates of health professionals from public health sectors in Bahir

\footnotetext{
*Competing interests: The authors declare that they have no any financial or non-financial competing interests.

Authors' contributions: KA designed the study, coordinated the field work, analyzed the data and drafted the manuscript. GT \& TE participated in design the study, drafting of the manuscript and review of the article.
}

Dar city were found to be $39.6 \%$. Age, sex, marital status, educational status, workplace, current salary, professional category and work experience were the main factors associated with health professionals' attrition from public health sectors. Conclusion: The findings showed that the level of health professionals' attrition is high in the study area. Policy makers and health mangers should design appropriate retention strategies for health professionals at public health sectors in terms of most associated factors with attritions of health professionals to reduce the prevalence of health professionals' attrition from public health sectors in collaboration with development partners and concerned body.

Keywords: HRH; Health Professionals; Attrition; Public Health Sectors

\section{BACKGROUND}

The global shortage of human resources for health (HRH) limits access to effective health services for many, particularly the poor and the most vulnerable, and hinders progress towards health and development goals. Yet, estimates suggested that there is a shortage of 4.2 million health workers worldwide. Africa has been facing unprecedented human resource for health crisis for years. Out of 57 countries experiencing critical shortage of human resource for health in the world 36 are located in Africa. The shortage is most severe in Sub Saharan African countries; thus, these countries will meet few of the health (MDGs) by 2015 [1].

Health workers in Africa have been very low and unable to match the rapidly growing population and need. Indeed, Sub Saharan Africa (SSA) has the least ratio of health workers to population in the world. Although, bench mark with regards to what should be an adequate 
health workers density level is difficult. The WHO report states that 2.3 Health workers per 1000 people are required to attain the coverage of essential health service and Core MDG related health service [1,2].

The joint learning initiative (2004) estimated the average number of Health workers in SSA countries to be about one health workers per 1000 people compared to 10 per 1000 in Norway and Finland. Concerning the density of doctors and nurses, the regional difference enormous is too low to be 0.022 per 1000 in Malawi, and nurse midwifery density ranges from 22 per 1000 in Finland to only 0.22 nurse and midwife per 1000 in Ethiopia [3].

In Ethiopia, as it is also the case elsewhere in the developing world, shortage of health workers, geographical imbalance in the number of health workers and increasing attrition are among the most pressing problems of health system. Ethiopia has about 0.027 physician per 1000 people. This is 3.5 times lower than the Sub-Saharan country which has the average of 0.1 per 1000 people [4].

Ethiopia has a total of 66,314 health workforce currently in service which including 30,950 health extension workers. The extension program is one of the strategies used to narrow the gap of health workforce shortage and access the preventive service to the community at grass root level. The national health worker ratio per 1000 people is 0.84 . This result is far less than the standard set by the WHO of 2.3 per 1000 people $[5,6]$.

The health workforce shortage is linked with decreased student enrollment in health training institution, failure of employing professional at the right time and high attrition among those already employed. A key contributor to the human resource for health crisis is attrition of health workforce measured by the numbers of health workforces who permanently leave their posts [7-14].

The attrition of health professionals from public health institution is aggravated by inadequate pay, sex, and weak performance management, place of work and experience of health professionals $[8,9,15]$.

All types of health professionals are needed to deliver health intervention-from public to clinical health service, from primary to tertiary care. After all, without a motivated, competent, protected and well-founded health workforce, there is a danger that the achievement of health related MDGs addresses health problem of the nation. In spite of a main view that studies on human resource for health attrition are scarce, many diverse statistical sources at different levels of our health system showed that the attrition of health professionals from public health sectors is high. In Ethiopia, the public health system is the major provider of health care service to the people. In particular, the poor segment of community uses public hospital, health centers and clinic, since the private health facilities are inaccessible and unaffordable to them. Therefore, managing such problems should be evidence-based and this study aims to assess the magnitude and factors associated with health professionals' attrition from public health sectors.

\section{METHODS}

\subsection{Study Setting and Sample}

A health facility based cross-sectional study was conducted in Bahir Dar City, Northwest Ethiopia. The sample size was calculated using single population proportion formula using the following parameters: 95\% confidence level (1.96), Margin of error (0.05), Expected prevalence of health professional 50\%. All inclusive sampling technique was used to select public health institutions and health professional's documents from public sectors in Bahir Dar. A total of 727 health professionals documents were reviewed from Sep-Oct, 2012.

\subsection{Data Collection and Processing}

Structured questionnaire was originally prepared in English according to the objective of the study and translated in to the local language (Amharic) and back to English again in order to maintain the validity of instrument. The questionnaires were pre-tested for its understandability by $5 \%$ of sample size in similar population which was not included in the study. Ten diploma graduated data collectors were recruited and trained on the sampling procedure, technique and data collection methods. Principal investigators and two BSc nurse trained supervisors monitored the overall quality of the data collection. The data were entered and analyzed using SPSS version 16. Descriptive statistics (frequencies proportion and chi-square test) were used to describe the study population in relation to relevant variables. Odds ratio was computed to see strength of association. To identify independent predictors of health professional attritions, only variables that were statistically significant during bivariate analysis were entered into multiple logistic regression models to control the effect of confounders. The test was two-sided and $\mathrm{P}<0.05$ was considered statistically significant. We reported the results as adjusted odds ratio (AOR) and 95\% confidence intervals.

\subsection{Ethical Considerations}

Ethical clearance was obtained from Ethical Review Board of Bahir Dar University. Permission was obtained from Amhara Regional health Bureau. Written informed consent was obtained from human resource head after clear explanation about the purpose of the study.

\section{RESULTS}

\subsection{Socio-Demographic Characteristics of the Study Participants}

A total of 727 health professional documents were re- 
viewed from public health facilities resulting a response rate of $100 \%$, The study included all the health care professional's documents who were working at different administrative, RHB, Woreda health office, Regional laboratory, and Health facilities in the study area. The mean age of the study subjects was 35.01 years (+SD), $\mathrm{SD}=8.27$, and the age ranged from 21 to 60 years. Three hundred sixty four $(50.1 \%)$ of the study subjects were Female. Three hundred forty three (47.2\%) had Diploma, 479 (59.3\%) married and 306 (42.1\%) were all type of Nurses in professional category. While 213 (29.3\%) of the study subjects had work experience 0 - 5 years and 446 (61\%) were working in Feleghiwote referral Hospital where as $576(79.6 \%)$ of health professional categorized under mid-level health professional who have diploma and first degree (Table 1).

Table 1. Socio-demographic characteristics of health professional in Bahir-Dar health sectors from January 1, 2007 to December 30, $2011(\mathrm{~N}=727)$.

\begin{tabular}{|c|c|c|}
\hline Characteristics & No. & $\%$ \\
\hline \multicolumn{3}{|l|}{ Age in years } \\
\hline $20-29$ & 256 & 35.2 \\
\hline $30-39$ & 278 & 38.2 \\
\hline $40-49$ & 144 & 19.9 \\
\hline $50+$ & 49 & 6.7 \\
\hline \multicolumn{3}{|l|}{ Sex } \\
\hline Male & 363 & 49.9 \\
\hline Female & 364 & 50.1 \\
\hline \multicolumn{3}{|l|}{ Educational status } \\
\hline Diploma & 343 & 47.2 \\
\hline First degree & 264 & 36.3 \\
\hline Second degree & 120 & 16.5 \\
\hline \multicolumn{3}{|l|}{ Marital status } \\
\hline Never married & 225 & 31.1 \\
\hline Married & 431 & 59.3 \\
\hline Divorced & 71 & 9.6 \\
\hline \multicolumn{3}{|l|}{ Health professional categories } \\
\hline Nurse (All nurse) & 306 & 42.1 \\
\hline Health officer & 52 & 7.2 \\
\hline Medical Dr. & 95 & 13.1 \\
\hline Pharmacy professional & 77 & 10.6 \\
\hline Laboratory professional & 65 & 8.9 \\
\hline Environmental health professional & 26 & 3.6 \\
\hline
\end{tabular}

Continued

\begin{tabular}{|c|c|c|}
\hline Master in public health & 68 & 9.4 \\
\hline X-ray technician & 38 & 5.2 \\
\hline \multicolumn{3}{|l|}{ Work experience of health professional } \\
\hline 0 - 5 years & 213 & 29.3 \\
\hline $6-10$ years & 172 & 23.7 \\
\hline $11-15$ years & 184 & 25.3 \\
\hline $16-20$ years & 89 & 22.2 \\
\hline $21+$ & 69 & 9.5 \\
\hline \multicolumn{3}{|l|}{ Type of health professional operator institution } \\
\hline Health center & 112 & 15.4 \\
\hline Hospital & 446 & 61.3 \\
\hline Woreda health office & 23 & 3.2 \\
\hline Regional laboratory & 19 & 2.6 \\
\hline Regional health Bureau & 127 & 17.5 \\
\hline \multicolumn{3}{|l|}{ Level of health professional } \\
\hline High level (Masters, MD and specialist) & 148 & 20.4 \\
\hline Mid-level (first degree and diploma) & 579 & 79.6 \\
\hline \multicolumn{3}{|l|}{ Current salary (\$) } \\
\hline $48-88$ & 462 & 63.5 \\
\hline $89-134$ & 184 & 25.3 \\
\hline $135-190$ & 53 & 7.3 \\
\hline 191 and above & 28 & 3.9 \\
\hline \multicolumn{3}{|l|}{ Higher institution training site } \\
\hline Government & 619 & 85.1 \\
\hline Private & 108 & 14.9 \\
\hline
\end{tabular}

\subsection{The Magnitude of Health Professional Attrition from Public Sectors (January, 2007-December, 2011)}

The attrition rate of Health professionals from public sector was $39.6 \%$ to all professionals category/cadre. The attrition rate with Health professional category was Medical Doctors 77.90\%, MPH 72.1\%, environmental Health $46.2 \%$, Pharmacy $44.2 \%$, Health officer $44.2 \%$, Laboratory 32.3 ), Nurse $22.9 \%$. Whereas the attrition rate was substantially different by type of health facility they work in Amhara Regional Health Bureau and Feleghiwote referral Hospital lost $66.9 \%$ and $40.6 \%$ of their Health professionals respectively, compared with HCs in Bahir Dar 9.8\%, Bahir Dar city administration woreda Health office $26.1 \%$ and Bahir Dar Regional Laboratory $26.3 \%$ for last five years (2007-2011) these showed to us 
there was marked difference in the attrition rate of Health professionals by working facility (Figures 1 and 2).

\subsection{Attrition of Health Professionals by Cadre for Last Five Years (2007-2011)}

The attrition of Health professional from public Health sectors were high in the year 2007, 2011 and 2008, 2009 for nurse and Medical Dr. respectively and seems the attrition for year 2011. But the attrition of health professional category like laboratory professionals and MPH still increasing. The possible reason for these may be in year 2007-2009 ART sites expanded to more Health centers. So that more nurse and Medical Dr have jobs opportunity at NGOS for mentoring (Figure 3).

\subsection{Means of Health Professionals Leaving from the Public Health Sectors, in Bahir Dar (2007-2011)}

The main means of Health professionals' attrition at each level of Health professionals and facility, when reviewed from the HRH document was at all cadres com-

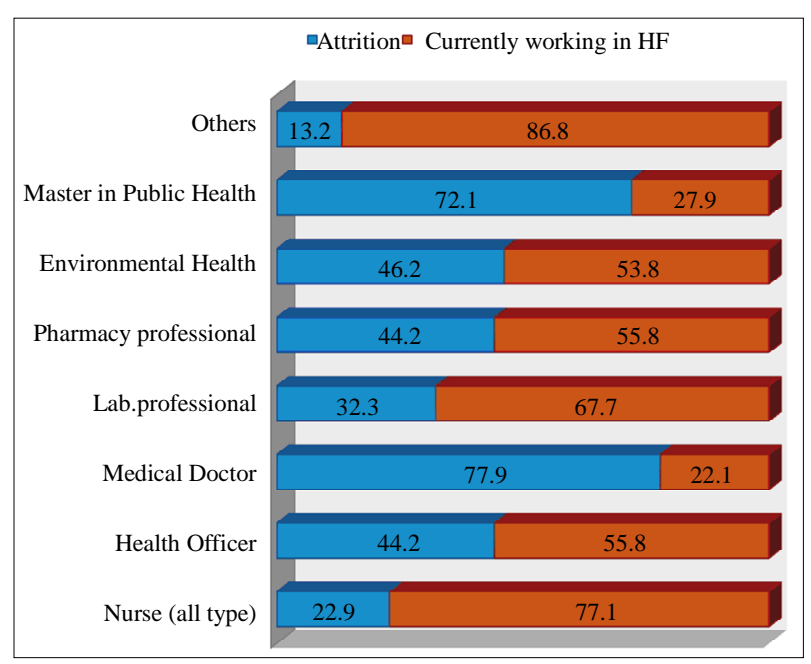

Figure 1. Attrition of health professionals with health cadres in Bahir Dar, October, 2012.

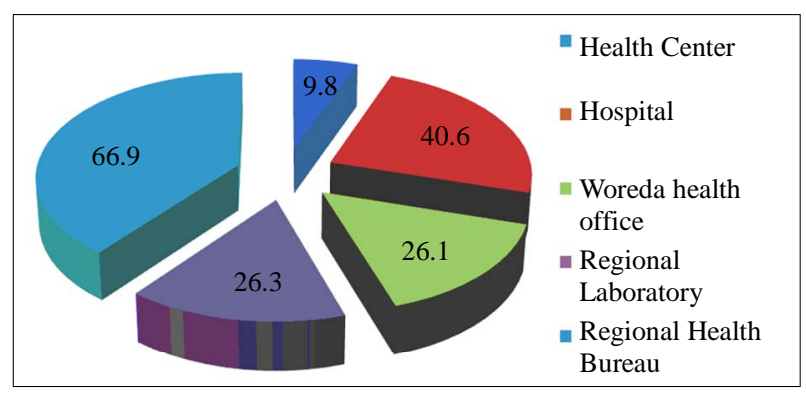

Figure 2. The attrition of health professionals from different health institution in Bahir Dar, for last five years (2007-2011) in \%, October, 2012. bined resignation accounted $79.5 \%$ from the total attrition of Health professionals from public Health sectors which was followed by $7.6 \%$ for transferred out, $6.9 \%$ for education upgrade, $2.1 \%$ for dismissal, $0.7 \%$ for death and 3.1\% for others like (pension and etc). Resignation was the leading reason for loss of Health professionals from public Health institutions, Pharmacy 100\%, environmental health 91.7\%, Medical Dr. 81.1, Nurse $78.6 \%$ and Laboratory professionals $76.2 \%$, while the leading cause of attrition among Health officers and others (like x-ray, nutrition, and health education) was transferred out and upgrade education (Figure 4).

\subsection{Factors Associated with Health Professionals' Attrition from Public Health Sectors}

After doing bivariate analysis for socio-economical characteristics with respected to health professional attritions; variable which were significant (p-value < 0.05) during bivariate analysis were further considered in to multivariate analysis was employed in order to control

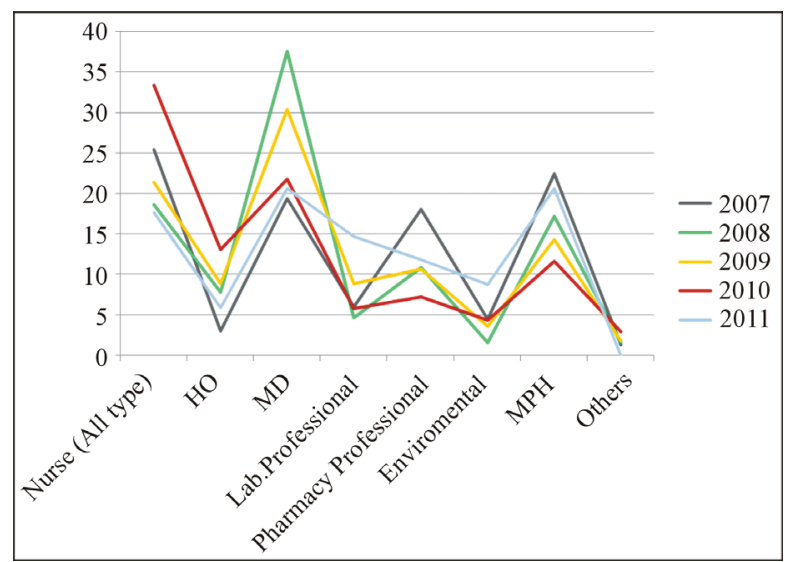

Figure 3. Health professional's attrition from public health sectors in Bahir-Dar for last five years (2007-2011) in \%.

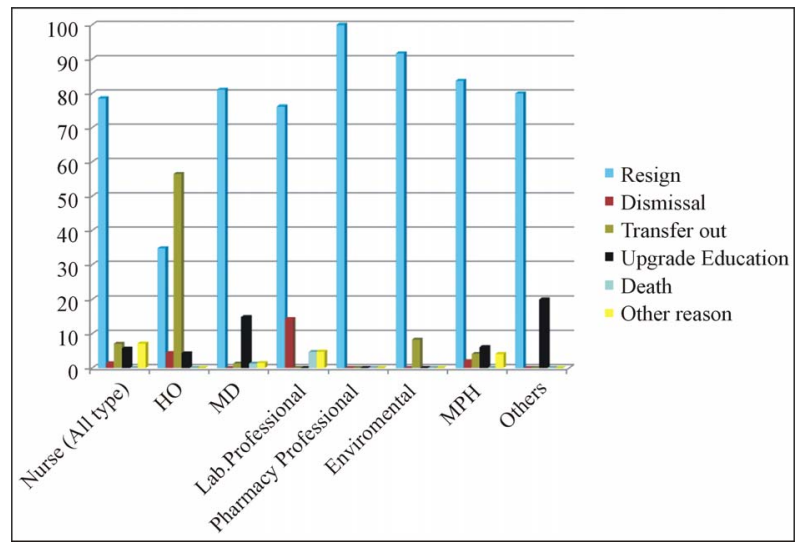

Figure 4. Means of Health professional's attrition from public Health in Bahir Dar (2007-2011) in \%. 
potential confounding factors by putting important covariates, step by step, in to model. The adjusted odds ratio (AOR) and the p-value after multivariate analysis were used to determine significance.

Age, Sex, Education, Marital status, Workplace, Health professional's category, Work experience and currentsalary of Health professionals was a strong predictor of Health professionals' attrition from public Health sectors.

The age of Health professionals was significantly associated with attrition. Health professionals whose age 30 - 39 years old, 40 - 49 years old, $50+$ years was 2.15, 7.39 and 5.05 times more likely to leave their jobs from public Health sectors than Health professionals with the age of $20-29$ years old $(\mathrm{AOR}=2.15$, 95\% CI: 1.12 , 4.16), (AOR = 7.39, 95\% CI: 2.59, 21.04), (AOR = 5.05, 95\% CI: 1.25 , 20.42) respectively, The attrition finding of Health professional for sex showed that male left their jobs 2.45 times as compared to Female (AOR $=2.45$, 95\% CI: 1.529, 3.965), Similarly, Health professionals whose education first degree $(\mathrm{AOR}=5.04,95 \% \mathrm{CI}: 2.42$, 10.49) and Second degree (AOR $=22.72$, 95\% CI: 6.95, 74.22) were leaving public Health institutions in study period as compared to the Health professionals that have educational at diploma level. The Health professionals attrition in study period was statically associated with marital status; those Health professionals never married and married 27.58 and 11.45 times more likely to leave the public Health sectors as compared to Divorced Marital status with AOR (27.52, 95\% CI: 6.69, 113.62 and 11.45, 95\% CI: $2.94,44.58)$ respectively. In addition, the attrition of Health professionals was more significant and associated with Health professionals working place, working in Hospitals, Regional laboratory and RHB. They were 11.02, 8.43 and 12.98 times more likely to leave their job as compared with Health professionals working in HCs AOR and 95\% CI \{(11.02, 4.51, 26.97), (8.43, 1.36, 51.79), (12.98, 4.33, 38.90)\}, respectively. The finding of attrition was more significant with Health professional's category. All type of Nurses (AOR $=4.76$, 95\% CI: 1.35, 16.80), Health officers (AOR $=20.25$, 95\% CI: 4.53, 90.55), Medical (AOR = 60.71, 95\% CI: 13.64, 270.21), Laboratory Professionals (AOR $=4.71$, 95\% CI: 1.03, 21.52), Pharmacy (AOR = 7.94, 95\% $\mathrm{CI}: 2.03,31.03)$, Environmental professional $(\mathrm{AOR}=$ 6.75, 95\% CI, 1.20, 37.92) and MPH (AOR = 7.12, 95\% CI, 1.34, 37.92) these findings showed that being medical Dr and HO in Health professionals category was 60.71 and 20 times at risk to leave the public Health sector as compared as other Health professionals (like X-ray technician, nutrition, physiotherapy and Health education). The other factors associated with health professional attrition from public Health sectors in the study period was work experience of Health professionals, as multivariate analysis result showed as Health professionals with work experience 6 - 10 years and 11 - 15 years were 4.08 and 4.22 times at risk as compared with Health professionals work experience 0 - 5 years with AOR and 95\% CI (4.08, 2.13, 7.82 and 4.22, 1.85, 9.64) respectively, where as the work experience above 16 years was not associated with Health professionals attrition from public Health sectors. Salary showed a statistically strong association with Health professional's attrition. Those whose current monthly salary from $48 \$-88 \$$ and from $89 \$-134 \$$ were 85.99 and 10.66 times exposed to leave their jobs from public Health sectors as compared with Health professionals earn monthly salary of $191 \$$ and above in study period (Table 2).

\section{DISCUSSION}

The prevalence of health professional's attrition from public health sectors was $39.6 \%$ in the study area. The attrition rate among health professional category was 77.9\% for Doctors, $72.1 \%$ for $\mathrm{MPH}, 22.9 \%$ for Nurse, 44.2\% for Pharmacy, $44.2 \%$ for Health Officer, 32.3\% for laboratory. This figure was relatively higher when compared to other similar study finding from East Wollega, which was $47.2 \%$ for high level professionals like Doctors, $19.3 \%$ mid-level like health officers and Nurse and Kenya, 38\% for Doctors, but the attrition of nurse in Kenya was high than this study $40 \%[8,9]$. But the attrition of health professionals from public health sectors was almost similar with study conducted in East Harergae zone, Ethiopia that revealed $76 \%$ for Doctors and $54 \%$ for midlevel health professional like nurse and health officers [16]. This finding was also supported with qualitative data findings. The Key-informant said that; "Like any Ethiopian Region, proportion of health professional that left from public health institution in Bahir Dar city was high, the problem was sever for high professional level like Doctors and Master. Most health professionals left the public health sectors with short period of experience to work for private and NGOs sector".

According to their level of education, the proportion of health professionals left the public health sectors were 5.04 and 22.72 times higher for degree and second degree with AOR (5.04, 95\% CI: 2.42, 10.48) and AOR (22.72, 95\% CI: 6.95, 74.22), respectively compared to diploma. Hence, educational level has a statistically significant difference.

In this finding, the attrition of Health professionals from public health sectors was substantially differing by type of Health facility they work. Amhara Regional Health Bureau 66.9\%, Felegehiwote referral hospital 40.6\%, HCs in Bahir Dar 9.8\%, Bahir Dar city district 26.1\%, Bahir Dar Regional Laboratory 26.3\%. But the finding of Health workforce attrition in public Health sector of Kenya revealed that there is no substantial va- 
Table 2. Factors associated with attrition of Health professionals from public Health sectors in Bahir Dar Health institutions, January 1, 2007 to December $302011(\mathrm{~N}=727)$.

\begin{tabular}{|c|c|c|c|c|c|}
\hline \multirow{3}{*}{ Variables } & \multicolumn{2}{|c|}{ Health professional attrition } & \multirow{2}{*}{\multicolumn{2}{|c|}{ OR (95\% CI) }} & \multirow{3}{*}{$\mathrm{p}$-value for AOR } \\
\hline & \multirow{2}{*}{$\begin{array}{c}\text { Yes } \\
\text { Number }\end{array}$} & \multirow{2}{*}{$\begin{array}{c}\text { No } \\
\text { Number }\end{array}$} & & & \\
\hline & & & Crude & Adjusted & \\
\hline \multicolumn{6}{|l|}{ Age in years } \\
\hline $20-29$ & 56 & 200 & 1.00 & 1.00 & \\
\hline $30-39$ & 137 & 141 & $3.47(2.38,5.07)$ & $2.15(1.11,4.16)$ & 0.022 \\
\hline $40-49$ & 76 & 68 & $3.99(2.57,6.21)$ & $7.39(2.59,21.03)$ & $<0.001$ \\
\hline $50+$ & 19 & 30 & $2.26(1.18,4.32)$ & $5.05(1.25,20.41)$ & 0.023 \\
\hline \multicolumn{6}{|l|}{ Sex } \\
\hline Male & 194 & 169 & $3.30(2.41,4.51)$ & $2.45(1.52,3.90)$ & $<0.001$ \\
\hline Female & 94 & 270 & 1.00 & 1.00 & \\
\hline \multicolumn{6}{|l|}{ Educational status } \\
\hline Diploma & 83 & 260 & 1.00 & 1.00 & \\
\hline First degree & 108 & 156 & $2.17(1.53,3.07)$ & $5.04(2.42,10.48)$ & $<0.001$ \\
\hline Second degree & 97 & 23 & $13.21(7.87,22.16)$ & $22.72(6.955,74.22)$ & $<0.001$ \\
\hline \multicolumn{6}{|l|}{ Marital status } \\
\hline Never married & 108 & 118 & $11.90(4.62,30.65)$ & $22.58(6.69,113.62)$ & $<0.001$ \\
\hline Married & 175 & 256 & $8.887(3.51,22.52)$ & $11.45(2.94,44.58)$ & $<0.001$ \\
\hline Divorced & 5 & 65 & 1.00 & & \\
\hline \multicolumn{6}{|l|}{ Health professional category } \\
\hline Nurse (All type) & 70 & 236 & $1.99(0.74,5.20)$ & $4.76(1.35,16.80)$ & 0.015 \\
\hline Health officer & 23 & 29 & $5.23(1.76,15.54)$ & $20.25(4.53,90.55)$ & $<0.001$ \\
\hline Medical Dr. & 74 & 21 & $23.26(8.07,67.00)$ & $60.71(13.64,270.21)$ & $<0.001$ \\
\hline Lab. Personnel & 21 & 44 & $3.15(1.07-9.23)$ & $4.71(1.03,21.52)$ & 0.046 \\
\hline Phar. profession & 34 & 43 & $5.22(1.84,14.80)$ & $7.94(2.03,31.03)$ & 0.003 \\
\hline Environmental & 12 & 14 & $5.66(1.68,19.09)$ & $6.75(1.20,37.92)$ & 0.030 \\
\hline Master in public health & 49 & 19 & $17.02(5.78,50.10)$ & $7.12(1.34,37.93)$ & 0.021 \\
\hline X-ray technician & 5 & 33 & 1.00 & 1.00 & \\
\hline \multicolumn{6}{|l|}{ Level of health professional } \\
\hline Mid-level & 179 & 400 & 1.00 & & \\
\hline High-level & 109 & 39 & $6.25(4.16,9.37)$ & & \\
\hline \multicolumn{6}{|l|}{ Current salary (\$) } \\
\hline $48-88$ & 108 & 133 & $0.71(0.41,1.25)$ & 85.99 (26.26, 265.28) & $<0.001$ \\
\hline $89-2134$ & 70 & 159 & $0.39(0.22,0.69)$ & $10.66(3.78,30.07)$ & $<0.001$ \\
\hline $135-190$ & 77 & 118 & $0.57(0.32,1.02)$ & $2.37(0.99,5.65)$ & 0.051 \\
\hline 1911 and above & 33 & 29 & 1.00 & 1.00 & \\
\hline
\end{tabular}




\begin{tabular}{|c|c|c|c|c|c|}
\hline Work place & & & & & \\
\hline Health center & 11 & 101 & 1.00 & 1.00 & \\
\hline Hospital & 181 & 265 & $6.27(3.27,12.02)$ & $11.02(4.51,26,97)$ & $<0.001$ \\
\hline Woreda health office & 6 & 17 & $3.24(1.06,9.93)$ & $3.56(0.84,15.05)$ & 0.084 \\
\hline Regional laboratory & 5 & 14 & $3.28(0.99 .10 .84)$ & $8.43(1.37,51.77)$ & 0.021 \\
\hline Regional health bureau & 85 & 42 & 18.58 (9.01 - 38.32) & 12.98 (4.33, 38.88) & $<0.001$ \\
\hline \multicolumn{6}{|l|}{ Work experience in years } \\
\hline $0-5$ & 41 & 172 & 1.00 & 1.00 & \\
\hline $6-10$ & 88 & 84 & $4.39(2.79,6.91)$ & $4.08(2.13,7.82)$ & $<0.001$ \\
\hline $11-15$ & 99 & 85 & $4.89(3.12,7.64)$ & $4.22(1.85,9.64)$ & $<0.001$ \\
\hline $16-20$ & 46 & 43 & $4.49(2.62,7.68)$ & $2.13(0.67,6.74)$ & 0.197 \\
\hline $21+$ & 14 & 55 & $1.07(0.54,2.10)$ & $0.74(0.20,2.75)$ & 0.654 \\
\hline
\end{tabular}

Higher institution training site

$\begin{array}{cccc}\text { Government } & 266 & 353 & 2.91(1.77,4.77) \\ \text { Private } & 22 & 88 & 1.00\end{array}$

riation by type of health facility: provincial hospital lost an average of $4 \%$ of their health workers, compared to $3 \%$ for district hospital and 5\% for health centers. This may be due to health system difference of Ethiopia and Kenya. Moreover, may be Kenya pay adequate salary for health professionals [9].

The result of the present study depicted that sex of health professionals had significant association with health professional attrition from public health sectors. In this finding showed that male left their jobs 2.45 times as compared to Female (AOR $=2.45,95 \% \mathrm{CI}: 1.53$, 3.96). Similarly study in Kenya showed that the attrition rate for gender showed that more Males left their job as compared to Females $(\mathrm{AOR}=2.07,95 \% \mathrm{CI}: 1.67,3.74)$ $[8,17]$.

In this finding, the attrition of health professionals from public Health sectors was highly associated with current salary of Health professionals. This result was similar with study conducted in Ghana in 2010 [18-21]. This finding was also supported by finding of qualitative data. Key informant said; "most health professional leave the public health sectors to get fair salary to cover the cost of living”. This due to the salary paid at public health institution is not enough to cover the current living cost.

In this finding, the main reason of health professional attrition from public Health sectors at each level of facility and professionals was resigned accounted 79.5\% from the total reasons given followed by $7.6 \%$ for transferred out, $6.9 \%$ for upgrade education, $2.1 \%$ for dismissal, $0.7 \%$ for death and 3.1\% for pension. But a study conducted in Kenya, 2005, differed from this study. The main reason in Kenya was at each level of Health facility and when looking at all cadres combined were retirement (accounting for $48 \%$ to $58 \%$ of the total attrition at average facility, followed by resignation and death). This difference may be due to the difference of socio-demographic character of the study area or Kenya Ministry of health might pay adequate salary for public Health professionals [9,22].

In both FGD and in-depth interview session, Health professionals, managers and human resource mangers stressed on push and pull factor of Health professionals' attrition from public Health sectors. The most common push factors listed by FGD and in-depth interview participants were inadequate salary and remuneration, weak performance management of Health sectors, poor working environments, lack of professional development and career, lack of transfer and promotion, lack of recognitions for good work, infrequent supervision and support, stress to heavy work overload. In addition, the most common pull factors of recipient organization are the reverse of these. This finding was also similar in a study conducted in East Harerge [16], in Addis Ababa (2004) [11], and in Ghana (2010) [21,23-25].

\section{LIMITATIONS}

Even though health professionals' attritions expected to be high in rural area of public health institutions, this study was done in urban public health institutions and the study was based on cross-sectional data, which means 
that the direction of causal relationships between attritions and predictor variables can't be determined. In addition, despite retrospective document review was used, which was difficult to get all documents of after leaving the health institution that may underestimated the magnitude of health professionals attrition.

\section{CONCLUSION}

From this study we can conclude that the prevalence of health professionals' attrition from public health sector is high (39.6\%). The health professionals' attrition highly varies across professional categories. Age, sex, education, marital status, workplace, health professional's category, work experience and current-salary of health professionals were strong predictors of health professionals' attrition from public health sectors. Overall, the findings have important policy implications for health professional retentions and support the view that investing in health professionals may have substantial benefits to the health system effectiveness. Reducing health professional's attrition from public health sectors involves providing better essential health service for the entire population and achieving MDGs at large.

\section{ACKNOWLEDGEMENTS}

The authors acknowledge Intra health International Ethiopia for funding this research. Special acknowledgement also goes to Bahir Dar University for facilitating the ethical clearance to Amhara Regional health Bureau. Our deep gratitude again goes to study participants, data collectors and supervisors and the head of respective health sectors for their permission to review their health facility records.

\section{REFERENCES}

[1] World Health Report (2006) Health workforce. WHO, Geneva.

[2] WHO (2007) Estimates of health personnel: Physicians, nurses, mid-wives, dentists, and pharmacists? WHO, Geneva.

http://www.who.int/hrh/documents/counting_health_work ers.pdf

[3] Joint Learning Initiative Strategy Report (2004) Human resources for health: Overcoming the crisis. Mass. Harvard University Press, Cambridge.

[4] Ethiopia a Country Status Report on Health and Poverty (2004) World Bank Africa Region Human Development and Ministry of Health of Ethiopia.

[5] Planning and Programming Department (2007) Health and health related indicators. FMOH, Addis Ababa, Ethiopia.

[6] Africa Health Workforce Observatory (2010) Human resource for health profile country Ethiopia.

[7] Yumkella, F. (2006) Retention of health care workers in low-resource settings: Challenges and responses. Capac- ity Project, 1, 1-6.

[8] Slavea, C., Stephen, M. and Gilbert, K. (2009) Health workforce attrition in the public sector in Kenya: A look at the reasons. Human Resource for Health, Biomed Central.

[9] Jundia, T. (2008) The magnitude, patterns and determinate of factors of health workers migration from public health sector. East Harergie Zone of Oromia, Eastern Ethiopia.

[10] Awases, M., Gbary, A., Nyoni, J. and Chatora, R. (2004) Migration of health professionals in six countries: Synthesis report. WHO.

[11] Tefera, B. (2004) Determinant of internal and out migration of physician from the public sectors. Addis Ababa University.

[12] Fetu, Y. (2005) Retention: Health workforce issues and response action in low-resource setting.

[13] Berhan, Y. (2006) Medical doctors profile in Ethiopia: Production, attrition and retention. In memory of 100year Ethiopian modern medicine \& the new Ethiopian millennium.

[14] Onzubo, P. (2007) Turnover of health professional in general hospitals in west Nile region.

[15] Michael, Y., Jira, C., Girma, B. and Tushune, K. (2010) Health workforce, deployment, attrition and density in east wollega zone, Western Ethiopia. Ethiopian Journal of Health Sciences, 20, 213-222.

[16] Mathauer and Imhoff (2004) Motivation of health workers maters in health care: The case of Benin and Kenya.

[17] Mathauer, I. and Imhoff, I. (2003) Staff motivation in Africa: The impact of non-financial incentives and quality management tools: A way to retain staff. Eschborn, GTZ.

[18] Ministry of Health (2004) Human resources in the health sector: Towards a solution. Government of Malawi, and Lilongwe, Malawi.

[19] Gilson, L. and Mills, A. (1995) Health sector reform in sub-Saharan Africa: Lessons of the last ten years. Health Policy, 32, 215-243. http://dx.doi.org/10.1016/0168-8510(95)00737-D

[20] World Bank \& Ministry of Health Ethiopia (2004) A country status report on health and poverty.

[21] John, A., Peter, Q. and John, A. (2010) Key determinant of migration among health professional in Ghana.

[22] Chris, R. (2010) Nursing human resource in Kenya, case study.

[23] Otaala, B. and Mahlalela, P. (2004) Proceedings of the workshop on enhancement of leadership in higher education. 27-29 September 2004, University of Namibia, Windhoek.

[24] Tesfaye, M. (2005) Motivation of health workers in Jimma, south west Ethiopia.

[25] World Health Organization (2010) Polices and practice of countries that are experiencing a crisis in human resource for health: Tracking survey. No. 6 . 